\title{
Predictors for thromboembolism in patients with cholangiocarcinoma
}

\author{
Christian Pfrepper ${ }^{1}\left[\right.$ - Maren Knödler ${ }^{2} \cdot$ Ruth Maria Schorling $^{2} \cdot$ Daniel Seehofer $^{3} \cdot$ Sirak Petros $^{1,4} \cdot$ Florian Lordick $^{2}$
}

Received: 15 April 2021 / Accepted: 4 September 2021 / Published online: 9 September 2021

(c) The Author(s) 2021

\begin{abstract}
Background Patients with cancer are at increased risk of thromboembolic events contributing significantly to cancer-related morbidity and mortality. Because cholangiocarcinoma is a rare type of cancer, the incidence of thromboembolism in this patient population is not well defined.

Methods Patients with cholangiocarcinoma treated at the University Cancer Center Leipzig between January 2014 and December 2018 were analyzed retrospectively regarding the incidence of arterial and venous thromboembolism.

Results A total of 133 newly and consecutively diagnosed patients were included, of whom $22 \%$ had stage IV disease. Thromboembolism was diagnosed in 39 (29.3\%), with $48 \%$ of the events occurring between 60 days prior and 30 days after the initial diagnosis. Arterial thrombosis accounted for $19 \%$ and portal venous thrombosis for $33 \%$ of the events, while the rest of events occurred in the non-portal venous system. In multivariable analysis, an ONKOTEV score $\geq 2$ was the only independent predictor for thromboembolism. Serum CA 19-9 was available in 87 patients (65.4\%). In this subgroup, CA 19-9 above the median of $97.7 \mathrm{U} / \mathrm{ml}$ and vascular or lymphatic compression were independent predictors for thromboembolism in the first year and CA 19-9 alone remained a significant predictor over the whole observation period. An ONKOTEV score $\geq 2$ and increasing age were predictors of survival.

Conclusions A very high thromboembolic risk was observed in cholangiocarcinoma, comparable to the risk situation in pancreatic and gastric cancer. The ONKOTEV score and serum CA 19-9 are independent predictors of thromboembolic events. Prospective validation of our observations in this patient population is warranted.
\end{abstract}

Keywords Cholangiocarcinoma $\cdot$ Thromboembolism $\cdot$ Risk prediction $\cdot$ ONKOTEV score $\cdot$ Khorana score

Christian Pfrepper

christian.pfrepper@medizin.uni-leipzig.de

1 Department of Hematology, Cellular Therapy and Hemostaseology, Division of Hemostaseology, University of Leipzig Medical Center, Liebigstr. 20, 04103 Leipzig, Germany

2 Department of Medicine (Oncology, Gastroenterology, Hepatology, Pulmonology, and Infectious Diseases), University Cancer Center Leipzig (UCCL), University of Leipzig Medical Center, Leipzig, Germany

3 Department of Visceral, Vascular, Thoracic and Transplant Surgery, University of Leipzig Medical Center, Leipzig, Germany

4 Medical ICU, University of Leipzig Medical Center, Leipzig, Germany

\section{Introduction}

Venous and arterial thromboembolism (VTE, ATE) are frequent complications in patients with cancer. The incidence of VTE in patients with cancer is significantly higher than in the general population, with reported annual rates between 0.5 and $20 \%$, depending on the specific cancer subpopulation, compared to annual incidence rates of $0.1-0.2 \%$ in non-cancer patients (Heit 2015; Horsted et al. 2012). VTE is also among the leading causes of death in cancer patients. The occurrence of thrombotic events is a negative prognostic factor beyond direct VTE-related mortality, underlining the complex interaction between the hemostatic system and malignancy (Chew et al. 2006; Khorana et al. 2007; Sorensen et al. 2000).

Several risk assessment models (RAM) for the stratification of VTE risk have been introduced. Most RAM build on the Khorana score (Khorana et al. 2008), which classifies gastric and pancreatic cancer as very high-risk tumor entities 
with thromboembolism (TE) rates of 15-30\%, lymphoma or lung, gynecologic, bladder and testicular cancers as high risk and all other cancer types as low risk (Ay et al. 2010; Cella et al. 2017; Godinho et al. 2020; Khorana et al. 2008; Pabinger et al. 2018). In addition, high platelet count, low hemoglobin, leukocytosis, and a body mass index $(\mathrm{BMI})>35 \mathrm{~kg} /$ $\mathrm{m}^{2}$ are predictors for the calculation VTE risk in the Khorana score. The Protecht score added points for gemcitabineor platin-based chemotherapy to the Khorana score (Verso et al. 2012). The ONKOTEV score included metastatic disease and vascular/lymphatic compression by the tumor as well as a history of VTE as predictors for VTE, which were equally weighted as a Khorana score $>2$. The ONKOTEV score has proved to be highly predictive for VTE in patients with pancreatic cancer (Godinho et al. 2020).

Cholangiocarcinoma (CC) is a relatively rare type of cancer. Due to the low incidence, patients with $\mathrm{CC}$ were not included into the calculation of currently established RAMs. Thus, CC is counted as a low-risk entity for the prediction of VTE. Knowledge on the TE risk in patients with $\mathrm{CC}$ is limited to case reports, small case series (Blasi et al. 2018; Blum et al. 2016; Jang et al. 2006; Sasaki et al. 2020; Schorling et al. 2020; Yuri et al. 2014) and two retrospective case-control studies. Jeon et al. reported a VTE rate of $14.7 \%$ within a median follow-up of 14.4 months after initial diagnosis (Jeon et al. 2012), while 19.4\% of patients undergoing hepatic resection had portal vein thrombosis in another study (Lu et al. 2016).

The aim of this study was to provide more evidence on the incidence and risk factors of VTE and ATE in patients with CC. In addition, the Khorana, Protecht (Verso et al. 2012) and ONKOTEV scores were evaluated regarding their performance in CC.

\section{Patients and methods}

The prospectively maintained database of the University Cancer Center Leipzig (UCCL) was screened for patients with the diagnosis of CC treated between January 1st 2014 and December 31st 2018. Data regarding sex, age, medical history, tumour localisation, disease stage, treatment biomarkers including blood count, liver and renal function parameters at baseline as well as thromboembolic complications were analysed.

\section{Calculation of risk factors for thrombosis}

Because thrombosis may precede the diagnosis of cancer (Navi et al. 2019a; White et al. 2005), all TE occurring within 60 days prior and all TE after the primary diagnosis of $\mathrm{CC}$ were considered cancer-associated. For the calculation of risk factors associated with tumor site or biomarkers, all thromboembolic events were taken into account. For the calculation of chemotherapy- or surgery-associated TE, only events within 6 months after the initiation of first or second-line chemotherapy and within 3 months after a surgical treatment were included and patients diagnosed with TE prior to therapy initiation were excluded. For the comparison between different treatment strategies, all thromboembolic events within 1 year after treatment initiation were included and patients diagnosed with TE prior to treatment were excluded. The calculation of the Khorana, Protecht and ONKOTEV scores is shown in the Supplementary Table 1.

\section{Statistics}

Descriptive statistics are displayed as median with absolute range or interquartile range (IQR) for quantitative variables and numbers (percentages) for qualitative data. Intergroup comparisons were performed using either $t$ test for normally distributed data or Mann-Whitney $U$ test otherwise. Categorical variables are shown with frequency (\%) and compared using Chi-square or Fisher's exact test. For the subgroup-analysis of frequencies of VTE, portal vein thrombosis (PVT) and ATE, patients with thrombotic events other than the analyzed were excluded. $p$ values $<0.05$ are considered statistically significant. The Kaplan-Meier estimation was used for survival analysis and the distribution was compared with log rank test. The Kaplan-Meier estimation for the development of TE was calculated for the whole observation period and in a second step, the follow-up of each patient was set to 6 months after the initial diagnosis. The time point was chosen, because most of the recently published studies evaluating the primary prophylaxis with low molecular weight heparin and direct oral anticoagulants had a follow-up period of 6 months (Bosch et al. 2020; Carrier et al. 2019; Khorana et al. 2019). A multivariable analysis for the development of TE and survival was conducted using a Cox-regression model. Statistical analysis was performed using the software SPSS version 25 (SPSS Inc, Chicago, IL).

\section{Ethical considerations}

The study was approved by the Ethics committee of the University of Leipzig (reference 180/20-ek), and conducted according to the declaration of Helsinki.

\section{Results}

We identified 137 patients with CC consecutively diagnosed and treated between 01.01.2014 and 31.12.2018 at the Leipzig University Hospital. Four patients were excluded due to lack of histology $(n=1)$, concomitant pancreatic cancer $(n=1)$, concomitant hepatocellular carcinoma $(n=1)$ and a 
histology showing neuroendocrine cancer $(n=1)$. Finally, 133 patients were included into the analysis. Median followup was 8.6 (IQR 3.7-18.0) months for all patients and 11.0 (IQR 5.2-21.8) months for the 66 patients who were alive at last follow-up. Baseline characteristics are given in Table 1.

\section{Antithrombotic treatment at primary diagnosis}

A total of 32 patients (24.1\%) received antithrombotic treatment at the time of diagnosis. Most patients received acetyl salicylic acid (aspirin, ASA, $n=18$ ) or a direct oral anticoagulant (DOAC, $n=9$ ) mainly for atrial fibrillation and coronary artery disease. Detailed information on antithrombotic treatment at the time of diagnosis, indication and history of thromboembolic events are displayed in Table 2.

A total of 39 of 133 patients (29.3\%) had venous or arterial thromboembolic events, diagnosed within a median of 40 days after the primary diagnosis of CC (range 57 days prior to 980 after the diagnosis of CC). Three patients had two thromboembolic events. This was a myocardial infarction followed by VTE in one, stroke followed by VTE in another and portal vein thrombosis followed by VTE in a third patient. Another patient experienced a postoperative thrombosis of the portal vein combined with thrombosis of the hepatic artery and the coeliac trunk, which was counted as one thrombotic event. Table 3 gives an overview over all 42 thrombotic events in these 39 patients.

The distribution of the thromboembolic events over time is shown in Fig. 1. The four events occurring later than 1 year after the primary diagnosis were all associated with persistent or progressive disease.

\section{Predictors of thromboembolic events}

\section{Biomarkers}

Patients with C-reactive protein (CRP) above the normal range had a VTE rate of $33.0 \%$ compared to $17.9 \%$ in patients with a normal CRP at initial diagnosis, $p=0.081$. Platelet count $\geq 350,000 / \mu \mathrm{l}$, leucocyte count $>11,000 / \mu \mathrm{l}$, and elevated bilirubin at primary diagnosis were not associated with an increased TE rate. CA 19-9 and CEA at primary diagnosis were measured in 87 and 66 patients, respectively. CA 19-9 was significantly higher in patients with a TE within the first year compared to those without TE [median: 324 (IQR 61-1567) U/ml vs. 83.3 (IQR 26-173) $\mathrm{U} / \mathrm{ml}, p=0.040]$, resulting in a 2.7 -fold increased risk for TE within the first year in patients with a CA 19-9 above the median of $97.7 \mathrm{U} / \mathrm{ml}$ (Supplementary Fig. 2). For the whole observation period, CA 19-9 above the median was associated with a trend towards a higher rate of TE (22.7 vs. $41.9 \%$, OR 3.6, $p=0.056)$. CA 19-9 was above the median in all five patients with ATE, in 6/14 (42.9\%) patients with VTE and in
Table 1 Baseline characteristics and treatment of 133 patients with cholangiocarcinoma

\begin{tabular}{|c|c|c|c|}
\hline \multicolumn{4}{|l|}{ Baseline characteristics } \\
\hline Female gender & $n(\%)$ & 61 & $45.9 \%$ \\
\hline Age & Median (range) & 67 & $31-82$ \\
\hline BMI & Median (range) & 25.5 & $16-43$ \\
\hline \multicolumn{4}{|l|}{ Diagnosis } \\
\hline Intrahepatic CC & $n(\%)$ & 77 & $57.9 \%$ \\
\hline Perihilar CC (Klatskin tumor) & $n(\%)$ & 48 & $36.1 \%$ \\
\hline Distal CC & $n(\%)$ & 8 & $6.0 \%$ \\
\hline \multicolumn{4}{|l|}{ Grading } \\
\hline Grade I & $n(\%)$ & 1 & $0.8 \%$ \\
\hline Grade II & $n(\%)$ & 53 & $39.8 \%$ \\
\hline Grade III & $n(\%)$ & 75 & $56.4 \%$ \\
\hline Grading not available & $n(\%)$ & 4 & $3.0 \%$ \\
\hline \multicolumn{4}{|l|}{ Stage according to UICC } \\
\hline I & $n(\%)$ & 13 & $9.8 \%$ \\
\hline II & $n(\%)$ & 35 & $26.3 \%$ \\
\hline III & $n(\%)$ & 54 & $40.6 \%$ \\
\hline IV & $n(\%)$ & 30 & $22.6 \%$ \\
\hline Staging not performed & $n(\%)$ & 1 & $0.8 \%$ \\
\hline Vascular/lymphatic compression & $n(\%)$ & 34 & $25.6 \%$ \\
\hline \multicolumn{4}{|l|}{ Khorana Score } \\
\hline 0 & $n(\%)$ & 72 & $54.1 \%$ \\
\hline 1 & $n(\%)$ & 49 & $36.8 \%$ \\
\hline 2 & $n(\%)$ & 8 & $6.0 \%$ \\
\hline 3 & $n(\%)$ & 4 & $3.0 \%$ \\
\hline \multicolumn{4}{|l|}{ ONKOTEV score } \\
\hline 0 & $n(\%)$ & 52 & $39.1 \%$ \\
\hline 1 & $n(\%)$ & 60 & $45.1 \%$ \\
\hline 2 & $n(\%)$ & 20 & $15.0 \%$ \\
\hline 3 & $n(\%)$ & 1 & $0.8 \%$ \\
\hline \multicolumn{4}{|l|}{ Treatment } \\
\hline Surgery & $n(\%)$ & 96 & $72.2 \%$ \\
\hline Without tumor resection & $n(\%)$ & 22 & $16.5 \%$ \\
\hline With tumor resection & $n(\%)$ & 74 & $55.6 \%$ \\
\hline Chemotherapy & $n(\%)$ & 50 & $37.6 \%$ \\
\hline Alone & $n(\%)$ & 8 & $6.0 \%$ \\
\hline With surgery \pm other therapies & $n(\%)$ & 37 & $27.8 \%$ \\
\hline With other therapies alone & $n(\%)$ & 5 & $3.8 \%$ \\
\hline Photon radiotherapy & $n(\%)$ & 15 & $11.3 \%$ \\
\hline SIRT/TACE/Chemosaturation & $n(\%)$ & 27 & $20.3 \%$ \\
\hline Photodynamic therapy & $n(\%)$ & 4 & $3.0 \%$ \\
\hline Best supportive care alone & $n(\%)$ & 11 & $8.3 \%$ \\
\hline
\end{tabular}

$C C$ cholangiocarcinoma, SIRT selective internal radiation therapy, TACE transarterial catheter chemoembolization, ICC: Union internationale contre le cancer

7/9 (77.9\%) patients with PVT and known CA19-9 at initial diagnosis ( $p=0.045$ for the comparison between VTE and ATE). There was a higher median CA19-9 in patients with PVT (312 [IQR 146-1929] U/ml vs. 83 [IQR 29-282] U/ 
Table 2 Antithrombotic medication at initial diagnosis, indication and history of thrombotic events

\begin{tabular}{lll}
\hline $\begin{array}{l}\text { Antithrombotic medication at time of initial diagnosis of } \\
\text { cholangiocarcinoma }\end{array}$ & $n$ & $\%$ \\
\hline No & 101 & 75.9 \\
ASA & 18 & 13.5 \\
Direct oral anticoagulant & 9 & 6.8 \\
Low molecular weight heparin & 1 & 0.8 \\
Vitamin K antagonist & 4 & 3.0 \\
Indication for antithrombotic medication* & & \\
Atrial fibrillation & 12 & 9.0 \\
Coronary heart disease & 12 & 9.0 \\
History of stroke & 9 & 6.8 \\
Peripheral artery disease & 2 & 1.5 \\
History of venous thromboembolism & 2 & 1.5 \\
Primary prophylaxis & 2 & 1.5 \\
History of thromboembolic events $>60$ days prior to & & \\
diagnosis & & \\
Venous thromboembolism & 7 & 5,3 \\
Arterial thrombotic events & 11 & 8.3 \\
Stroke & 7 & 5.3 \\
Myocardial infarction & 3 & 2.3 \\
Recurrent stroke & 1 & 0.8 \\
\hline
\end{tabular}

ASA acetyl salicylic acid

*Seven patients had more than one indication for anticoagulation

$\mathrm{ml}, p=0.043)$ and a trend towards a higher median CA19-9 in patients with ATE (409 [IQR 279-871] U/ml vs. 83 [IQR 29-282] U/ml, $p=0.065$ ) compared to patients without TE, respectively. CEA was not predictive for TE.

\section{Treatment}

The risk of developing TE within 12 months after initiation of any cancer-related therapy was $19.5 \%$ (22/113 eligible patients), while the 6-month risk after initiation of chemotherapy was $22.7 \%$ (10/44 eligible patients, 6 VTE, 3 PVT, 1 ATE). The 3-month risk for postoperative TE was $12.2 \%$ (11/90 eligible patients, 6 VTE, 2 PVT, 2 ATE, 1 combined event) and $13.9 \%$ (10/62 eligible patients) after exclusion of patients without tumor resection. No patient who received best supportive care had TE after but $3 / 8$ patients prior to the initial diagnosis of $\mathrm{CC}$.

No difference in the 12-month risk of TE was seen between patients receiving chemotherapy versus no chemotherapy $(22.7 \%$ vs. $17.4 \% ; p=0.627)$, surgical treatment (operation $20.9 \%$, no operation $13.6 \%, p=0.559$ ) or a combination (chemotherapy alone $20.8 \%$, chemotherapy and surgery $14.3 \%, p=0.740$ ). Out of 44 patients without TE prior to the initiation of chemotherapy, 7 patients received capecitabin or gemcitabine alone and 37 patients received a platinum derivative. The 6-month rate of TE was $28.6 \%$ in the capecitabin or gemcitabine group versus $21.6 \%$ in the platinum group $(p=0.649)$.

\section{Cancer-associated risk factors}

No significant difference in the rates of TE was seen between metastatic and localized disease (39.4\% vs. $25.3 \%$, $p=0.120)$, vascular or lymphatic compression $(38.2 \%$ vs. $25.3 \%, p=0.148$ ), high-grade versus low and intermediate grade $(29.3 \%$ vs. $25.9 p=0.670)$ and extrahepatic versus intrahepatic CC $(25.0 \%$ vs. $31.2 \%, p=0.437)$. After
Table 3 Distribution of all thrombotic events

\begin{tabular}{lccc}
\hline & All events, $n(\%)$ & $\begin{array}{c}<6 \text { days prior and } \leq 30 \text { days } \\
\text { after initial diagnosis, } n(\%)\end{array}$ & $\begin{array}{l}>30 \text { days after } \\
\text { initial diagnosis, } \\
n(\%)\end{array}$ \\
\hline All events & $42(31.6)$ & $20(15.0)$ & $22(16.5)$ \\
Venous thrombotic events & $33(24.8)$ & $15(11.3)$ & $18(13.5)$ \\
DVT/PE & $16(12.0)$ & $6(4.5)$ & $10(7.5)$ \\
Portal vein thrombosis/VCI & $14(10.5)$ & $8(6.0)$ & $6(4.5)$ \\
Port-associated VTE & $2(1.5)$ & $0(0.0)$ & $2(1.5)$ \\
Phlebitis & $1(0.8)$ & $1(0.8)$ & $0(0.0)$ \\
Arterial thromboembolic events & $8(6.0)$ & $5(3.8)$ & $3(2.3)$ \\
Stroke & $5(3.8)$ & $3(2.3)$ & $1(0.8)$ \\
Peripheral arterial thrombosis & $1(0.8)$ & $0(0.0)$ & $0(0.0)$ \\
Hepatic artery thrombosis & $1(0.8)$ & $1(0.8)$ & $0(0.0)$ \\
Myocardial infarction & $1(0.8)$ & $1(0.8)$ & $1(0.8)$ \\
Combined events & & & \\
Thrombosis of the portal vein, & $1(0.8)$ & $0(0.0)$ & \\
hepatic artery and coeliac & & & \\
trunk & & &
\end{tabular}

$D V T$ deep vein thrombosis, $P E$ pulmonary embolism, $V C I$ vena cava inferior 


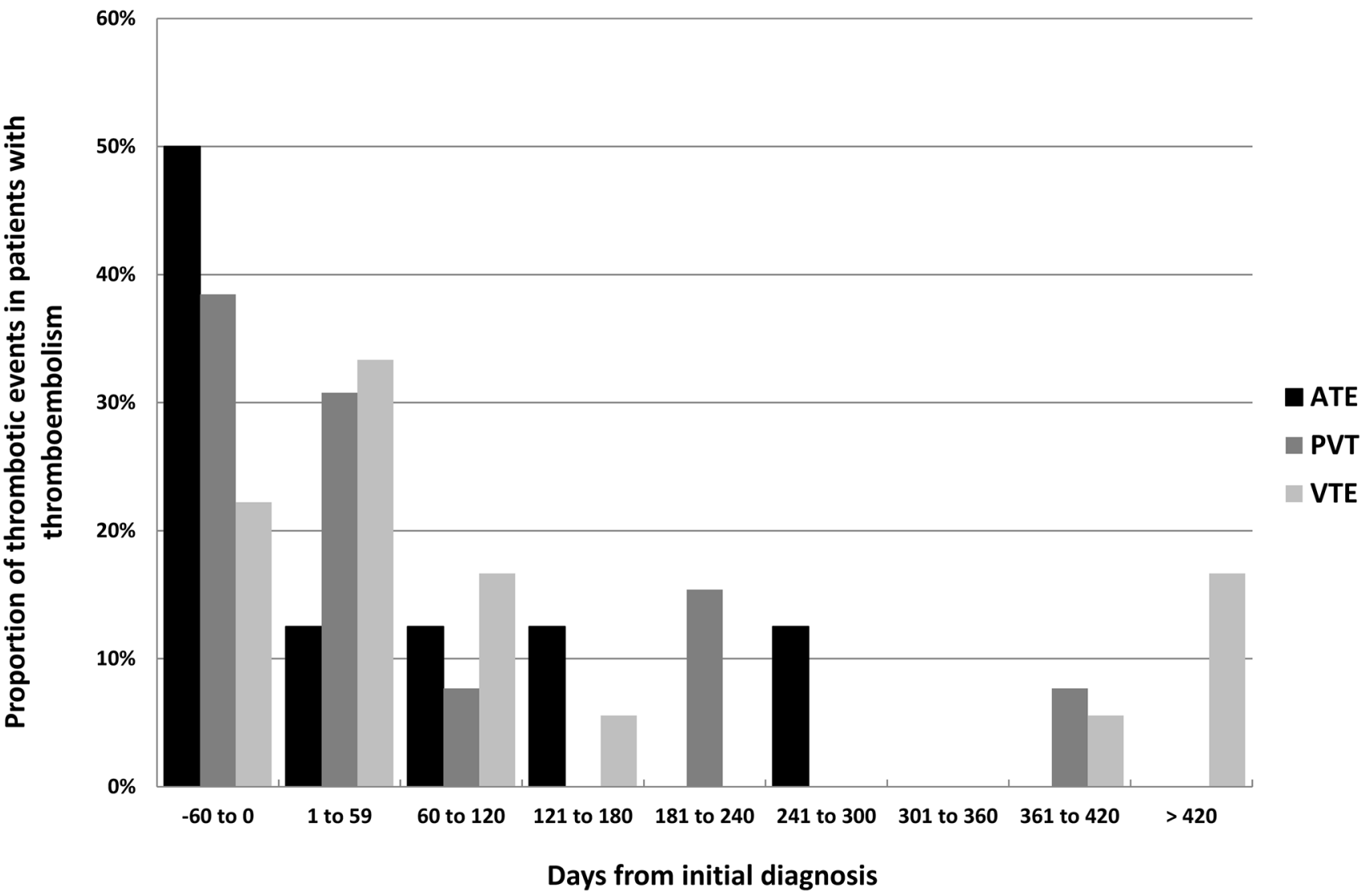

Fig. 1 Distribution of thromboembolic events over time. One combined thrombotic event was ommited. ATE arterial thrombotic event, $P V T$ portal vein thrombosis, VTE venous thromboembolism

exclusion of patients with ATE, 11/32 (34.4\%) patients with vascular or lymphatic compression had VTE or PVT compared to 18/92 (19.6\%) patients without vascular or lymphatic compression, $p=0.088$, which was mainly due to a trend to a higher rate of PVT in these patients $(22.2 \%$ vs. $8.6 \%$, OR 3.02, $p=0.060$ ).

Thromboembolic events in different patient groups are summarized in the Supplementary Table 2.

\section{TE rates according to Khorana, ONKOTEV and Protecht score}

When CC was counted as low-risk cancer, 5/12 (41.7\%) patients with Khorana score $\geq 2$ had a thromboembolic event compared to 33/121 (27.3\%) patients with Khorana score $<2, p=0.292$. There was no significant difference when CC was counted as high or very high-risk cancer entity. Khorana score was not predictive for VTE, PVT or ATE. When CC was counted as a low-risk cancer, patients with an ONKOTEV score $\geq 2$ had a higher TE rate (9/18, $50 \%$ ) compared to patients with a score $<2(29 / 115,25.2 \%)$, $p=0.030$. The difference was still significant when CC was counted as high risk $(10 / 21$ vs. $28 / 112, p=0.035)$. There was still a trend when $\mathrm{CC}$ was defined as a very high-risk entity (17/43 vs. $21 / 90, p=0.053)$. An ONKOTEV score $\geq 2$ was associated with a higher rate of PVT (35.7\% vs. $8.5 \%$, OR $5.97, p=0.004)$ and a trend to a higher rate of ATE $(25.0 \%$ vs. $6.5 \%$, OR $4.78, p=0.067)$ but not with a higher incidence of VTE ( $10.0 \%$ vs. $14.9 \%$, OR $0.64, p=1.00$ ). Patients receiving chemotherapy with a Protecht score $\geq 3$ had a TE rate of $47.8 \%$ compared to $29.6 \%$ in patients with a Protecht score $<3, p=0.186$. The rate of VTE, PVT and ATE was not different in the high and low-risk groups according to the Protecht score (Supplementary Table 2).

\section{Prediction of thrombotic events at different time points}

Taking into account the entire observation period, the risk of developing TE at 1 year was $25.6 \%$ in patients with an ONKOTEV score $<2$ and $57.7 \%$ in patients with an ONKOTEV score $\geq 2, p=0.002$ (Fig. 2a). This difference remained significant when CC was counted as high or very high-risk cancer entity (Supplementary Fig. 1). The risk of developing TE at 1 year in patients with a Khorana score $<2$ was $27.2 \%$ compared to $41.7 \%$ in patients with a Khorana 

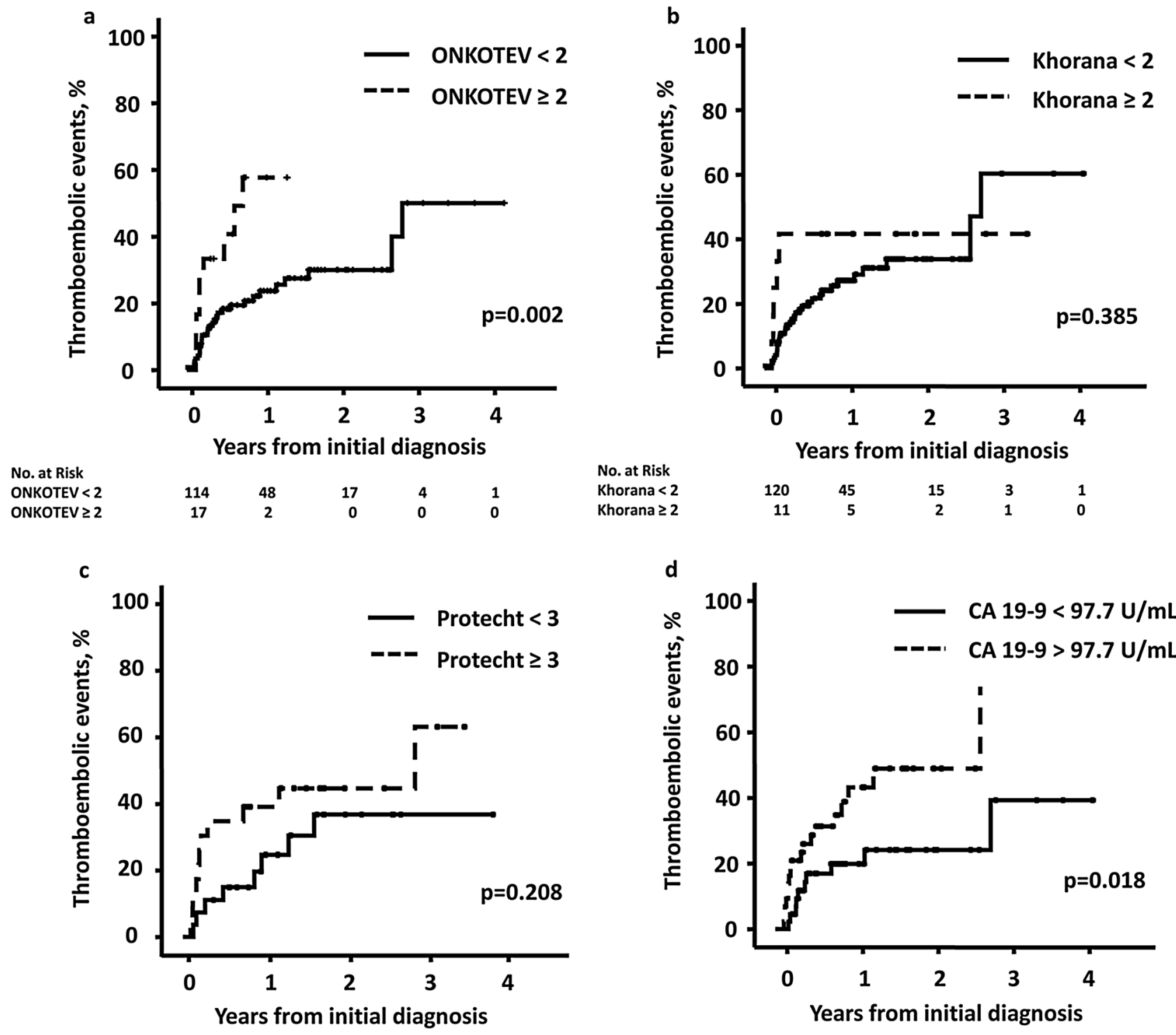

No. at Risk

Protecht $<3$

$\begin{array}{lllll}26 & 15 & 5 & 1 & 0 \\ 22 & 11 & 4 & 2 & 0\end{array}$

No. at Risk

$\begin{array}{llllll}\text { CA } 19-9<97.7 \mathrm{U} / \mathrm{mL} & 43 & 21 & 9 & 3 & 1 \\ \text { CA } 19-9<97.7 \mathrm{U} / \mathrm{mL} & 42 & 13 & 4 & 0 & 0\end{array}$

Fig. 2 Thromboembolic events according to a ONKOTEV score, b Khorana score, $\mathbf{c}$ Protecht score, and d median CA 19-9 (97.7 U/mL)

Score $\geq 2, p=0.385$ (Fig. 2b). The risk of developing TE at one and 2 years in patients receiving chemotherapy and a Protecht score $<3$ was 24.7 and $36.8 \%$ compared to 39.1 and $44.7 \%$ in patients with a Protecht score $\geq 3, p=0.208$, respectively (Fig. 2c). The one- and two-year TE rate in patients with CA 19-9 above the median compared to those with CA $19-9$ below the median was $43.2 \%$ vs. $20.0 \%$ and $48.9 \%$ vs. $24.1 \%, p=0.018$, respectively (Fig. 2 d).

When the final follow-up of all patients for the Kaplan Meier estimation was set to 6 months after initial diagnosis, the TE rate was $19.1 \%$ for ONKOTEV < 2 vs. $44.4 \%$ for ONKOTEV $\geq 2(p=0.008), 20.9 \%$ for Khorana score $<2$ vs. $41.7 \%$ for Khorana score $\geq 2(p=0.057)$, and $14.8 \%$ for
Protecht $<3$ vs. $34.8 \%$ for Protecht $\geq 3$. (Supplementary Fig. 3). There was no difference after exclusion of arterial thromboembolic events.

\section{Survival}

At last follow-up, $34.2 \%$ with TE compared to $55.8 \%$ in patients without TE were alive, $p=0.034$, odds ratio 2.4. Patients with surgical treatment had a median overall survival (OS) of 0.65 (95\% CI 0.48-0.82) years vs. 2.5 [95\% CI 1.9-3.1) years, $p<0.001$. Median OS was not different in patients who underwent surgery with cancer resection in curative intention (3.0 [95\% CI 0.86-5.07] years) or in 
patients who underwent exploratory laparotomy but were not resectable ( 2.5 [95\% CI 0.90-4.12] years), $\mathrm{p}=0.859$. The median OS for patients with TE was 0.7 [95\% CI 0.3-1.2] years vs. 1.6 [95\% CI 1.0-2.2] years for those without TE, $p=0.107$. Survival rates at 1 year and 2 years were $45.5 \%$ and $34.7 \%$, respectively, for patients with TE compared to $63.6 \%$ and $47.5 \%$ for those without a TE (Fig. 3a). Patients with a low ONKOTEV score had a significantly better survival. The 1-year overall survival in patients with an ONKOTEV score $<2$ vs. $\geq 2$ for CC counted as low-risk tumor was $64.3 \%$ vs. $35.4 \%, p=0.021$ (Fig. 3b). This difference was still significant, when CC was counted as a high or very high-risk tumor: $64.3 \%$ vs $39.5 \%, p=0.04$ and $67.6 \%$ vs. $38.3 \%, p=0.001$, respectively. The median OS in patients receiving chemotherapy and a Protecht score $\geq 3$ was 1.2

a
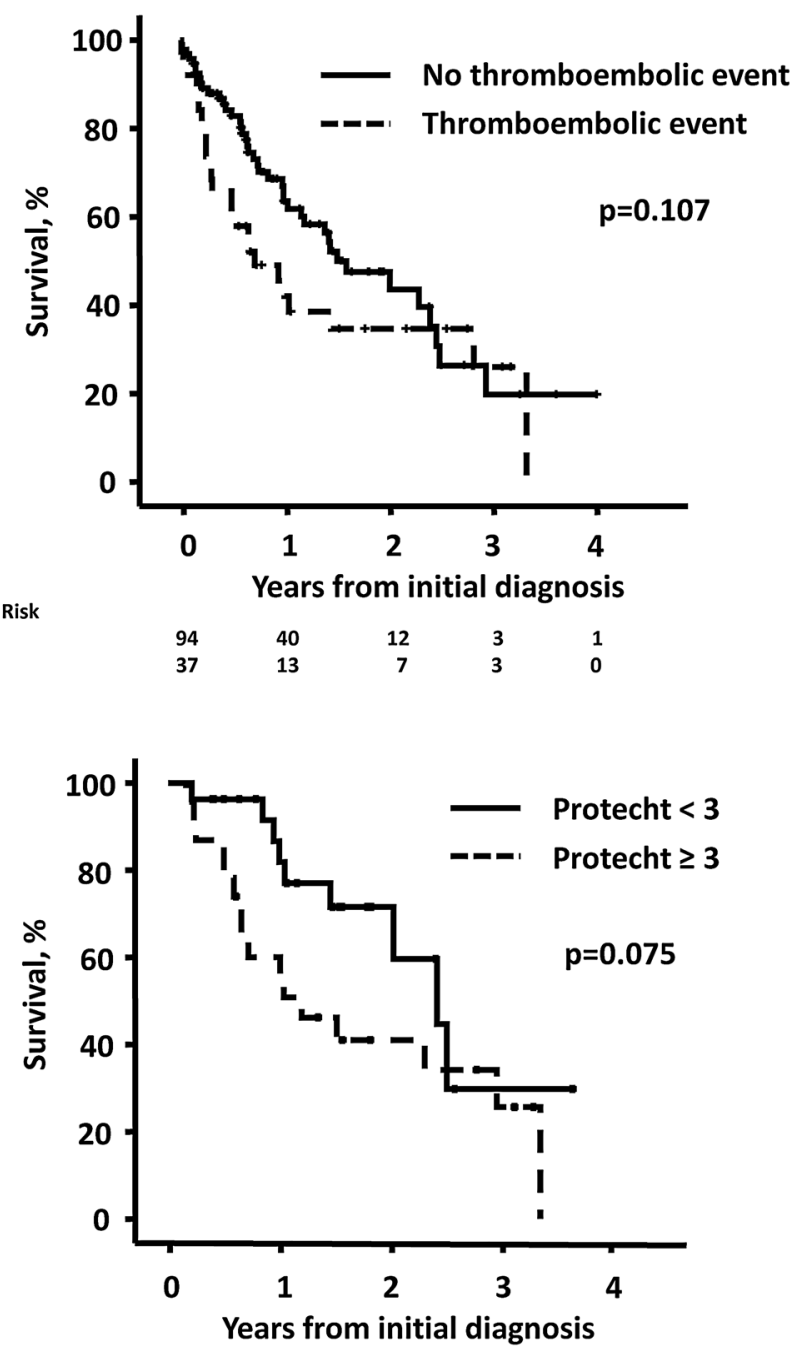

[95\% CI 0.46-1.9] years compared to 2.4 [95\% CI 1.6 vs. 3.3] years in patients with a Protecht score $<3, p=0.075$ (Fig. 3c). The 1- and 2-year survival in patients with CA 19-9 below the median compared to patients with CA 19-9 above the median was $65.0 \%$ vs. $44.4 \%$ and $49.0 \%$ vs. $31.8 \%$, $p=0.040$, Fig. $3 \mathrm{~d}$. There was no difference in survival of patients with a low or high Khorana score, regardless of the risk status. The median OS in different patient groups is summarized in the Supplementary Table 3.

\section{Predictors for poor survival in patients with thrombotic events}

Survival was less than 1 year in 25 and more than 1 year in 13 patients with TE. Three patients with TE surviving

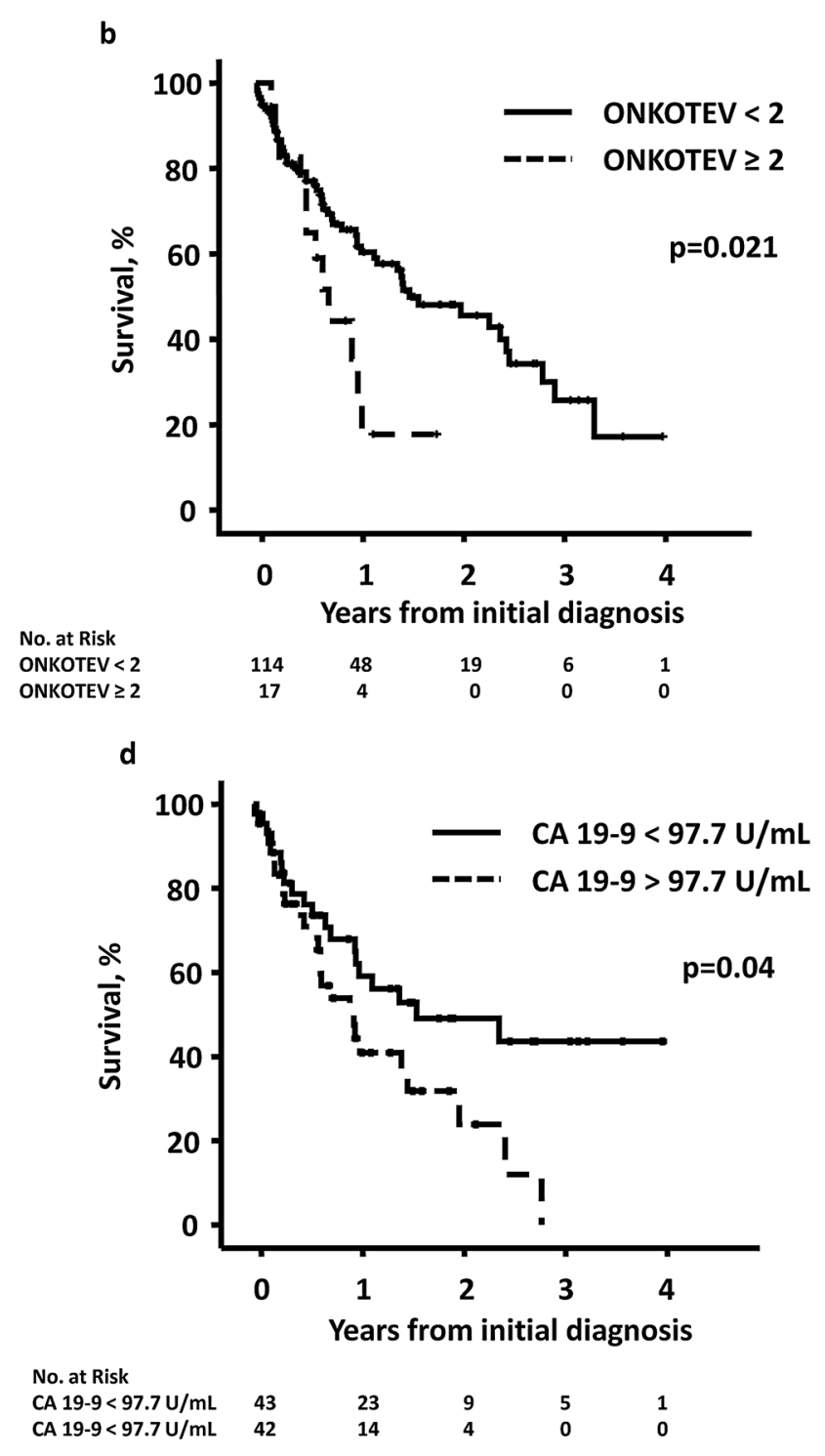

c
No. at Risk

Protecht $<3$ Protecht $\geq 3$
No. at Ris No TE TE

Fig. 3 Surviva embolic event 
less than 1 year were treated with best supportive care, the remaining patients received at least one treatment strategy. Patients with TE who survived less than 1 year were older (median age: 72 [IQR: 65-75] years vs. 64 [IQR 55-71] years), $p=0.048$, had a lower median BMI (24 [IQR: 21-28] $\mathrm{kg} / \mathrm{m}^{2}$ vs. 26 [IQR: $\left.\left.24-31\right] \mathrm{kg} / \mathrm{m}^{2}, p=0.023\right)$ and received chemotherapy less frequently ( $36.0 \%$ vs. $76.9 \%, p=0.038$ ). Survival was less than 1 year in $50 \%$ of the patients with VTE, $62 \%$ of the patients with PVT and $100 \%$ of the patients with ATE. No other significant risk factors for poor prognosis in patients with TE were found.

\section{Multivariable analysis}

A multivariable Cox-regression model was performed for the prediction of thromboembolic events including the potential cancer-associated risk factors: intrahepatic vs. extrahepatic CC, stage IV disease, vascular or lymphatic compression, Khorana score $>2$ and ONKOTEV score $\geq 2$, the blood biomarkers CRP $>$ upper limit of normal (ULN) and serum bilirubin > ULN and the baseline risk factors: age and BMI as continuous variables, history of TE and pre-existing anticoagulation with VKA or DOAC. For the prediction of survival, TE events were added. ONKOTEV score $\geq 2$ was the only independent predictor for TE in the first year and in the whole observation period. ONKOTEV score $\geq 2$ and age (increased relative risk of 3.4 [95\% CI 0.6-6.2\%] \% per year) were independent predictors for survival. When only the 87 patients with known CA19-9 values were included into the analysis, CA 19-9 above the median and vascular or lymphatic compression were independent predictors for TE in the first year, while CA19-9 above the median for TE in the whole observation period and ONKOTEV score $\geq 2$ and age for OS. The results of the multivariable analysis are summarized in Table 4.

\section{Discussion}

This study on consecutive patients treated at a tertiary referral cancer center in Germany revealed a TE rate in patients with CC of $29.3 \%$. Approximately $50 \%$ of the thromboembolic events occurred between 2 months prior and one month after the initial diagnosis, arterial events accounted for approximately $20 \%$ of all thromboembolic events and almost $42 \%$ of all VTEs occurred in the portal vein. The largest retrospective study to date on patients with CC reported 40 (14.7\%) TEs in 273 patients (Jeon et al. 2012). In that study, only 10 patients (25\%) had TE at initial diagnosis and only $14(35 \%)$ had VTE. The remaining cases were PVT $(n=18,45 \%)$ and thrombosis of the inferior vena cava $(n=4,10 \%)$ and the hepatic veins $(n=4,10 \%)$. However, there were no ATEs reported. Two other studies focused on PVT in patients undergoing liver resection for CC. Lu and colleagues retrospectively analyzed data from 303 patients at the time of liver resection and found tumor associated PVT in $19.3 \%$. Patients with a PVT had poorer survival and were more likely to have lymph node metastasis and elevated bilirubin levels ( $\mathrm{Lu}$ et al. 2016). In a prospective case series of $27 \mathrm{CC}$ patients admitted for liver resection without history of thrombosis, 6 (22.2\%) patients had TE (2 VTE and 4 PVT) within 60 days after surgery (Blasi et al. 2018). In our cohort, TE occurred in only $13.9 \%$ of all patients after tumor resection and these were mainly non-portal VTE.

\section{Arterial thromboembolic events}

The true incidence of ATE in CC is unknown. We found ATEs in $6.0 \%$ of our patients. A few case reports described CC patients having ATE (Dunn et al. 2017; Sasaki et al. 2020; Yuri et al. 2014). In our study, 50\% of ATE

Table 4 Results of the multivariable Cox-regression analysis

\begin{tabular}{|c|c|c|c|c|c|c|c|c|c|}
\hline & \multicolumn{3}{|l|}{$\mathrm{TE}$ in the first year } & \multicolumn{3}{|c|}{ TE in the whole observation period } & \multicolumn{3}{|l|}{ Survival } \\
\hline & Predictor & $\begin{array}{l}\mathrm{HR} \\
(95 \% \mathrm{CI})\end{array}$ & $p$ & Predictor & $\begin{array}{l}\mathrm{HR} \\
(95 \% \mathrm{CI})\end{array}$ & $p$ & Predictor & $\begin{array}{l}\text { HR } \\
(95 \% \mathrm{CI})\end{array}$ & $p$ \\
\hline All patients & ONKOTEV $\geq 2$ & $3.1(1.4-6.7)$ & 0.004 & ONKOTEV $\geq 2$ & $3.0(1.4-6.5)$ & 0.005 & $\begin{array}{l}\text { ONKOTEV } \geq 2 \\
\text { Age (per year) }\end{array}$ & $\begin{array}{l}1.9(1.0-3.7) \\
1.034(1.006- \\
1.062)\end{array}$ & $\begin{array}{l}0.048 \\
0.031\end{array}$ \\
\hline $\begin{array}{l}\text { Patients with } \\
\text { known CA } \\
19-9\end{array}$ & $\begin{array}{l}\text { CA } 19-9>\text { median } \\
\text { Vascular or } \\
\text { lymphatic com- } \\
\text { pression }\end{array}$ & $\begin{array}{l}2.4(1.0-5.7) \\
2.3(1.0-5.3)\end{array}$ & $\begin{array}{l}0.043 \\
0.048\end{array}$ & CA $19-9>$ median & $2.5(1.1-5.7)$ & 0.025 & $\begin{array}{l}\text { ONKOTEV } \geq 2 \\
\text { Age (per year) }\end{array}$ & $\begin{array}{l}2.2(1.1-4.7) \\
1.031(1.002- \\
1.062)\end{array}$ & $\begin{array}{l}0.037 \\
0.039\end{array}$ \\
\hline
\end{tabular}

The multivariable analysis included: age (continuous variable) and BMI (continuous variable), history of TE, pre-existing anticoagulation with VKA or DOAC, intrahepatic vs. extrahepatic disease, stage IV disease, vascular or lymphatic compression, Khorana score $>2$ and ONKOTEV score $\geq 2, \mathrm{CRP}>\mathrm{ULN}$, serum bilirubin $>\mathrm{ULN}$

$T E$ thromboembolism, BMI body mass index, VKA vitamin $\mathrm{K}$ antagonist, DOAC direct oral anticoagulant, CRP C-reactive protein, $U L N$ upper limit of normal 
preceded the diagnosis of CC. A large study on 374,331 patients $\geq 67$ years of age diagnosed with different types of cancer showed that the ATE rate within 6 months prior to the diagnosis of cancer is progressively increasing, with a sixfold increased risk compared to an age-matched cohort within the last month before cancer diagnosis (Navi et al. 2019a). Other studies showed a 2.2 fold increased risk of cancer diagnosis within 6 months after myocardial infarction (Rinde et al. 2017) and a 3.3 fold increase within 6 months after lower limb arterial thrombosis (Sundbøll et al. 2018). The risk of ATE is still elevated after cancer diagnosis but the highest risk is within the first month after cancer diagnosis (Navi et al. 2017, 2019b). Data from a US registry of patients with incident cancer showed a cumulative 6-month incidence of myocardial infarction of 2.6-3.1\% and of ischemic stroke of $3.5-3.8 \%$ in patients with gastric, pancreatic and colorectal cancer (Navi et al. 2017). In our cohort, 4 (3.0\%) ATE occurred prior or at the time of initial diagnosis, and 3 (2.3\%) ATE occurred within 6 months after the diagnosis of CC. A direct comparison between the results is not feasible due to the comparably low number of patients included in our study and the rather short observation period. Nevertheless, our data indicate that the risk of ATE in CC patients seems to follow the same pattern known from other tumor entities, with the highest risk shortly before and after the initial diagnosis.

\section{Prediction of thromboembolic events}

ONKOTEV score was the only independent predictor for TE in the first year of the observation period. The Khorana and the Protecht score showed a trend to a higher rate of TE within the first 6 months after initial diagnosis in the Kaplan Meier estimation. The data regarding the Protecht score should be interpreted with caution due to the limited number of 50 patients receiving chemotherapy, since the Protecht score can be assessed in that patient cohort only. In addition, only the Protecht score but not the ONKOTEV and the Khorana score are validated for the prediction of both arterial and venous thrombotic events. We found that an ONKOTEV score $\geq 2$ was associated with a trend to a higher ATE rate and that the TE rates were not different after exclusion of ATE. Lymphatic or vascular compression was associated with a trend to a higher rate of PVT and was an independent predictor for TE in the first year in the subgroup of patients with known CA 19-9. The fact that lymphatic or vascular compression is part of the ONKOTEV score might be the reason why the ONKOTEV score performed better in our study than the Khorana score.

Due to the lack of data regarding the performance of RAM for the prediction of TE in CC patients, the interpretation might be extrapolated from other tumor entities. Although patients with pancreatic and gastric cancer are better predicted by the Khorana score than lung cancer patients (van Es et al. 2020), the ONKOTEV score is highly predictive for VTE in patients with pancreatic cancer (Godinho et al. 2020). In that study, a Khorana score $>2$ did not predict TE while the ONKOTEV score and its components vascular compression and metastatic disease did. Similar to our study, $51 \%$ of patients had abdominal thrombosis that was mainly caused by vascular compression.

Apart from the ONKOTEV score, we have found a trend towards a positive association between TE rate and elevated plasma CRP levels. The association of CRP with TE in CC was already described in a Korean cohort of patients (Jeon et al. 2012). The strongest known predictive biomarker for TE is D-dimer. A recently published RAM included only D-dimer and the tumor entity to predict a 6-month VTE rate in cancer patients (Pabinger et al. 2018). Unfortunately, due to the retrospective design of our study, no D-dimer levels could be assessed, as this parameter is not part of the routine laboratory in our center. However, as there is a well-known correlation between D-dimer and CRP, patients with elevated CRP are likely to have also elevated D-dimer levels. The value of D-dimer in the prediction of TE in patients with CC should be addressed in prospective studies.

CA 19-9 was associated with an increased risk of TE in our study and it was also a predictor of poor survival in the univariate analysis. CA-19-9 is a well-established prognostic factor in patients with CC (Ali et al. 2007; Bergquist et al. 2016; Hahn et al. 2020; Li et al. 2017; Wang et al. 2013), but there are to the best of our knowledge no reports describing an association between CA 19-9 and the risk of TE in CC patients. It has been shown elsewhere that CA 19-9 correlated with the severity of VTE in patients with pancreatic cancer (Woei-A-Jin et al. 2016). CA 19-9 may serve as a surrogate marker to quantify mucins in blood as it binds to apomucins (Yue et al. 2011). Lu and colleagues showed that patients with mucinous CC have significantly higher CA 19-9 levels, were more likely to have vascular invasion and had poorer overall and disease free survival after hepatic resection (Lu et al. 2019). The injection of purified mucins into mice resulted in the formation of tissue factor independent platelet rich microthrombi via P-selectin and L-selectin activation (Wahrenbrock et al. 2003). The fact that CA 19-9 was above the median in all patients with ATE, but only in $42.9 \%$ of VTE patients, supports the assumption of a mainly platelet-dependent emergence of TE in patients with elevated CA 19-9 that might be related to a mucinous subtype.

\section{Comparison with other cancer types}

VTE rates in patients with pancreatic cancer ranged between $10 \%$ within 3 months after initiation of chemotherapy in a prospective study (Pelzer et al. 2015) and 20-40\% in different retrospective cohort studies (Epstein et al. 2012; Godinho 
et al. 2020; Khorana et al. 2013; Kruger et al. 2017; Menapace et al. 2011). The incidence of VTE in patients with gastric (GC) and esophageal cancer (EC) ranges between 9 and 20\% (Aonuma et al. 2019; Fuentes et al. 2018; Khorana et al. 2013; Lyman et al. 2013; Marshall-Webb et al. 2017; Starling et al. 2009). In contrast, the incidence of VTE in patients with colorectal cancer (CRC) is $10-12 \%$ in NorthAmerican cohorts (Khorana et al. 2013; Lyman et al. 2013), while it is $17 \%$ in an Asian cohort (Aonuma et al. 2019). The rate of TE was almost $30 \%$ in our study population and seems to be in the range of pancreatic and gastric cancer. We, therefore, propose that CC should be counted as a highrisk tumor entity. However, this should be validated in independent cohorts.

\section{Survival}

Survival in our cohort was predicted by a high ONKOTEV score and age, while TE failed to be predictive for survival in the Kaplan-Meier estimation. TE is a well-established unfavorable prognostic factor for survival in cancer patients and was associated with poor survival in CC patients (Jeon et al. 2012). The reason why TE was not associated with poor survival in our cohort might be explained by the limited number of patients included. However, this highlights the predictive value of the ONKOTEV score which was an independent predictive factor even after the inclusion of patients with known CA 19-9 into the analysis. As mentioned above, the inclusion of lymphovascular invasion in the ONKOTEV score may be the reason why the ONKOTEV score is highly predictive in patients with $\mathrm{CC}$, because lymphovascular invasion was shown to be an adverse prognostic factor for overall and disease free survival in patients with hilar CC type Bismuth IV (Li et al. 2017).

\section{Limitations}

Our study has several limitations due to its retrospective design, conduct in a monocentric setting, and the limited number of patients included into the analysis. Thus, the influence of minor risk factors may have been missed. In addition, CA $19-9$ was only available in $65 \%$ of patients, which limits conclusions from the multivariate analysis. Moreover, D-dimer as the strongest predictive blood-based biomarker for TE in cancer was not available in our study. Therefore, we were unable to calculate the D-dimer-based CATS score (Pabinger et al. 2018). In addition, other RAMs like the CONKO score (Pelzer et al. 2015) could not be calculated because the WHO performance score was not documented in our study and the Protecht score could only be calculated for a limited number of patients receiving chemotherapy. Nevertheless, and to the best of our knowledge, this study represents the first distinct and largest analysis of thromboembolic incidence and risk factors in patients with newly diagnosed $\mathrm{CC}$.

\section{Conclusion}

Our study showed that patients with $\mathrm{CC}$ have a high to very high risk of TE, comparable to that of patients with pancreatic and gastric cancers. In contrast to most other studies in cancer patients focusing mainly on venous TE, ATE accounted for about $20 \%$ of the TE in our cohort. In addition, half of the TE occurred between 2 months prior and one month after the initial diagnosis. An ONKOTEV score $\geq 2$ and CA 19-9 above the median are independent predictors for TE, while CA 19-9 was particularly predictive for ATE. The good performance of the ONKOTEV score in CC might be explained by the high rate of PVT in CC ( $42 \%$ of all venous thrombotic events) most likely caused by lymphatic and vascular compression.

Based on our findings, primary prophylaxis should be considered in patients with CC but particularly in those with high CA 19-9 levels and a high ONKOTEV score. Prospective studies including D-dimer and more RAMs are warranted in patients with $\mathrm{CC}$ to confirm these data.

Supplementary Information The online version contains supplementary material available at https://doi.org/10.1007/s00432-021-03794-1.

Author contributions CP was responsible for the design of the study, data collection, statistical analysis, interpretation of data and writing the manuscript. MK was responsible for the design of the study, data collection, interpretation of data and revising the manuscript. RMS was responsible for the design of the study and revising the manuscript. DS was responsible for the design of the study and revising the manuscript. SP was responsible for the design of the study, interpretation of data and revising the manuscript. FL was responsible for the design of the study, interpretation of data and revising the manuscript.

Funding Open Access funding enabled and organized by Projekt DEAL. The authors have not declared a specific grant for this research from any funding agency in the public, commercial or not-for-profit sectors.

Data availability Please contact author for data requests.

\section{Declarations}

Conflict of interest All authors have declared no conflicts of interest.

Open Access This article is licensed under a Creative Commons Attribution 4.0 International License, which permits use, sharing, adaptation, distribution and reproduction in any medium or format, as long as you give appropriate credit to the original author(s) and the source, provide a link to the Creative Commons licence, and indicate if changes were made. The images or other third party material in this article are included in the article's Creative Commons licence, unless indicated otherwise in a credit line to the material. If material is not included in the article's Creative Commons licence and your intended use is not 
permitted by statutory regulation or exceeds the permitted use, you will need to obtain permission directly from the copyright holder. To view a copy of this licence, visit http://creativecommons.org/licenses/by/4.0/.

\section{References}

Ali CW, Kaye TF, Adamson DJA, Tait IS, Polignano FM, Highley MS (2007) CA 19-9 and survival in advanced and unresectable pancreatic adenocarcinoma and cholangiocarcinoma. J Gastrointest Cancer 38:108-114. https://doi.org/10.1007/s12029-008-9019-x

Aonuma AO, Nakamura M, Sakamaki K, Murai T, Matsuda C, Itaya K, Sone T, Yagisawa M, Koike Y, Endo A, Tsukuda Y, Ono Y, Nagasaka A, Nishikawa S, Yamanaka T, Sakamoto N (2019) Incidence of cancer-associated thromboembolism in Japanese gastric and colorectal cancer patients receiving chemotherapy: a single-institutional retrospective cohort analysis (Sapporo CAT study). BMJ Open 9:e028563. https://doi.org/10.1136/bmjopen-2018-028563

Ay C, Dunkler D, Marosi C, Chiriac A-L, Vormittag R, Simanek R, Quehenberger P, Zielinski C, Pabinger I (2010) Prediction of venous thromboembolism in cancer patients. Blood 116:53775382. https://doi.org/10.1182/blood-2010-02-270116

Bergquist JR, Ivanics T, Storlie CB, Groeschl RT, Tee MC, Habermann EB, Smoot RL, Kendrick ML, Farnell MB, Roberts LR, Gores GJ, Nagorney DM, Truty MJ (2016) Implications of CA19-9 elevation for survival, staging, and treatment sequencing in intrahepatic cholangiocarcinoma: a national cohort analysis. J Surg Oncol 114:475-482. https://doi.org/10.1002/jso.24381

Blasi A, Molina V, Sanchez-Cabús S, Balust J, Garcia-Valdecasas JC, Taura P (2018) Prediction of thromboembolic complications after liver resection for cholangiocarcinoma: is there a place for thromboelastometry? Blood Coagul Fibrinolysis 29:61-66. https://doi. org/10.1097/MBC.0000000000000672

Blum MF, Ma VY, Betbadal AM, Bonomo RA, Raju RR, Packer CD (2016) Trousseau's syndrome in cholangiocarcinoma: the risk of making the diagnosis. Clin Med Res 14:53-59. https://doi.org/10. 3121/cmr.2015.1304

Bosch FTM, Mulder FI, Kamphuisen PW, Middeldorp S, Bossuyt PM, Büller HR, van Es N (2020) Primary thromboprophylaxis in ambulatory cancer patients with a high Khorana score: a systematic review and meta-analysis. Blood Adv 4:5215-5225. https:// doi.org/10.1182/bloodadvances.2020003115

Carrier M, Abou-Nassar K, Mallick R, Tagalakis V, Shivakumar S, Schattner A, Kuruvilla P, Hill D, Spadafora S, Marquis K, Trinkaus M, Tomiak A, Lee AYY, Gross PL, Lazo-Langner A, ElMaraghi R, Goss G, Le Gal G, Stewart D, Ramsay T, Rodger M, Witham D, Wells PS (2019) Apixaban to prevent venous thromboembolism in patients with cancer. N Engl J Med 380:711-719. https://doi.org/10.1056/NEJMoa1814468

Cella CA, Di Minno G, Carlomagno C, Arcopinto M, Cerbone AM, Matano E, Tufano A, Lordick F, de Simone B, Muehlberg KS, Bruzzese D, Attademo L, Arturo C, Sodano M, Moretto R, La Fata E, de Placido S (2017) Preventing venous thromboembolism in ambulatory cancer patients: the ONKOTEV study. Oncologist 22:601-608. https://doi.org/10.1634/theoncologist.2016-0246

Chew HK, Wun T, Harvey D, Zhou H, White RH (2006) Incidence of venous thromboembolism and its effect on survival among patients with common cancers. Arch Intern Med 166:458-464. https://doi.org/10.1001/archinte.166.4.458

Dunn T, Rudrapatna VA, Hesse S, Sargsyan Z (2017) Arterial thromboses heralding cholangiocarcinoma. Am J Med 130:e341-e342. https://doi.org/10.1016/j.amjmed.2017.02.020

Epstein AS, Soff GA, Capanu M, Crosbie C, Shah MA, Kelsen DP, Denton B, Gardos S, O'Reilly EM (2012) Analysis of incidence and clinical outcomes in patients with thromboembolic events and invasive exocrine pancreatic cancer. Cancer 118:3053-3061. https://doi.org/10.1002/cncr.26600

Fuentes HE, Oramas DM, Paz LH, Wang Y, Andrade XA, Tafur AJ (2018) Venous thromboembolism is an independent predictor of mortality among patients with gastric cancer. J Gastrointest Cancer 49:415-421. https://doi.org/10.1007/s12029-017-9981-2

Godinho J, Casa-Nova M, Moreira-Pinto J, Simões P, Paralta Branco F, Leal-Costa L, Faria A, Lopes F, Teixeira JA, Passos-Coelho JL (2020) ONKOTEV score as a predictive tool for thromboembolic events in pancreatic cancer-a retrospective analysis. The Oncol. https://doi.org/10.1634/theoncologist.2019-0510

Hahn F, Müller L, Jungmann F, Mähringer-Kunz A, Tanyildizi Y, Düber C, Galle PR, Weinmann A, Kloeckner R (2020) Survival prediction for patients with non-resectable intrahepatic cholangiocarcinoma undergoing chemotherapy: a retrospective analysis comparing the tumor marker CA 19-9 with cross-sectional imaging. J Cancer Res Clin Oncol 146:1883-1890. https://doi.org/10. 1007/s00432-020-03200-2

Heit JA (2015) Epidemiology of venous thromboembolism. Nat Rev Cardiol 12:464-474. https://doi.org/10.1038/nrcardio.2015.83

Horsted F, West J, Grainge MJ (2012) Risk of venous thromboembolism in patients with cancer: a systematic review and metaanalysis. PLoS Med 9:e1001275. https://doi.org/10.1371/journ al.pmed.1001275

Jang JW, Yeo CD, Kim JD, Bae SH, Choi JY, Jung ES, Rha SE, Byun JY, Yoon SK (2006) Trousseau's syndrome in association with cholangiocarcinoma: positive tests for coagulation factors and anticardiolipin antibody. J Korean Med Sci 21:155-159. https:// doi.org/10.3346/jkms.2006.21.1.155

Jeon HK, Kim DU, Baek DH, Ha DW, Lee BE, Ryu DY, Cheong JH, Kim GH, Am Song G, Jang AL (2012) Venous thromboembolism in patients with cholangiocarcinoma: focus on risk factors and impact on survival. Eur J Gastroenterol Hepatol 24:444-449. https://doi.org/10.1097/MEG.0b013e328350f93c

Khorana AA, Francis CW, Culakova E, Kuderer NM, Lyman GH (2007) Thromboembolism is a leading cause of death in cancer patients receiving outpatient chemotherapy. J Thromb Haemost 5:632-634. https://doi.org/10.1111/j.1538-7836.2007.02374.x

Khorana AA, Kuderer NM, Culakova E, Lyman GH, Francis CW (2008) Development and validation of a predictive model for chemotherapy-associated thrombosis. Blood 111:4902-4907. https://doi.org/10.1182/blood-2007-10-116327

Khorana AA, Dalal M, Lin J, Connolly GC (2013) Incidence and predictors of venous thromboembolism (VTE) among ambulatory high-risk cancer patients undergoing chemotherapy in the United States. Cancer 119:648-655. https://doi.org/10.1002/cncr.27772

Khorana AA, Soff GA, Kakkar AK, Vadhan-Raj S, Riess H, Wun T, Streiff MB, Garcia DA, Liebman HA, Belani CP, O'Reilly EM, Patel JN, Yimer HA, Wildgoose P, Burton P, Vijapurkar U, Kaul S, Eikelboom J, McBane R, Bauer KA, Kuderer NM, Lyman GH (2019) Rivaroxaban for thromboprophylaxis in high-risk ambulatory patients with cancer. N Engl J Med 380:720-728. https://doi. org/10.1056/NEJMoa1814630

Kruger S, Haas M, Burkl C, Goehring P, Kleespies A, Roeder F, Gallmeier E, Ormanns S, Westphalen CB, Heinemann V, Rank A, Boeck S (2017) Incidence, outcome and risk stratification tools for venous thromboembolism in advanced pancreatic cancer-a retrospective cohort study. Thromb Res 157:9-15. https://doi.org/10. 1016/j.thromres.2017.06.021

Li B, Xiong X-Z, Zhou Y, Wu S-J, You Z, Lu J, Cheng N-S (2017) Prognostic value of lymphovascular invasion in bismuth-corlette type IV hilar cholangiocarcinoma. World J Gastroenterol 23:6685-6693. https://doi.org/10.3748/wjg.v23.i36.6685

Lu CD, Wang K, Zhang CZ, Zhou FG, Guo WX, Wu MC, Cheng SQ (2016) Outcomes of intrahepatic cholangiocarcinoma with portal 
vein tumor thrombus following hepatic resection. J Gastroenterol Hepatol 31:1330-1335. https://doi.org/10.1111/jgh.13309

Lu J, Li B, Li F-Y, Ye H, Xiong X-Z, Cheng N-S (2019) Prognostic significance of mucinous component in hilar cholangiocarcinoma after curative-intent resection. J Surg Oncol 120:1341-1349. https://doi.org/10.1002/jso.25722

Lyman GH, Eckert L, Wang Y, Wang H, Cohen A (2013) Venous thromboembolism risk in patients with cancer receiving chemotherapy: a real-world analysis. The Oncol 18:1321-1329. https:// doi.org/10.1634/theoncologist.2013-0226

Marshall-Webb M, Bright T, Price T, Thompson SK, Watson DI (2017) Venous thromboembolism in patients with esophageal or gastric cancer undergoing neoadjuvant chemotherapy. Dis Esophagus 30:1-7. https://doi.org/10.1111/dote. 12516

Menapace LA, Peterson DR, Berry A, Sousou T, Khorana AA (2011) Symptomatic and incidental thromboembolism are both associated with mortality in pancreatic cancer. Thromb Haemost 106:371-378. https://doi.org/10.1160/TH10-12-0789

Moore RA, Adel N, Riedel E, Bhutani M, Feldman DR, Tabbara NE, Soff G, Parameswaran R, Hassoun H (2011) High incidence of thromboembolic events in patients treated with cisplatin-based chemotherapy: a large retrospective analysis. J Clin Oncol 29:3466-3473. https://doi.org/10.1200/JCO.2011.35.5669

Navi BB, Reiner AS, Kamel H, Iadecola C, Okin PM, Elkind MSV, Panageas KS, DeAngelis LM (2017) Risk of arterial thromboembolism in patients with cancer. J Am Coll Cardiol 70:926-938. https://doi.org/10.1016/j.jacc.2017.06.047

Navi BB, Reiner AS, Kamel H, Iadecola C, Okin PM, Tagawa ST, Panageas KS, DeAngelis LM (2019a) Arterial thromboembolic events preceding the diagnosis of cancer in older persons. Blood 133:781-789. https://doi.org/10.1182/blood-2018-06-860874

Navi BB, Howard G, Howard VJ, Zhao H, Judd SE, Elkind MSV, Iadecola C, DeAngelis LM, Kamel H, Okin PM, Gilchrist S, Soliman EZ, Cushman M, Safford M, Muntner P (2019b) The risk of arterial thromboembolic events after cancer diagnosis. Res Pract Thromb Haemost 3:639-651. https://doi.org/10.1002/rth2.12223

Pabinger I, van Es N, Heinze G, Posch F, Riedl J, Reitter E-M, Di Nisio M, Cesarman-Maus G, Kraaijpoel N, Zielinski CC, Büller HR, Ay C (2018) A clinical prediction model for cancer-associated venous thromboembolism: a development and validation study in two independent prospective cohorts. Lancet Haematol 5:e289-e298. https://doi.org/10.1016/S2352-3026(18)30063-2

Pelzer U, Opitz B, Deutschinoff G, Stauch M, Reitzig PC, Hahnfeld S, Müller L, Grunewald M, Stieler JM, Sinn M, Denecke T, Bischoff S, Oettle H, Dörken B, Riess H (2015) Efficacy of prophylactic low-molecular weight heparin for ambulatory patients with advanced pancreatic cancer: outcomes from the CONKO-004 trial. J Clin Oncol 33:2028-2034. https://doi.org/10.1200/JCO. 2014.55.1481

Rinde LB, Småbrekke B, Hald EM, Brodin EE, Njølstad I, Mathiesen EB, Løchen M-L, Wilsgaard T, Brækkan SK, Vik A, Hansen J-B (2017) Myocardial infarction and future risk of cancer in the general population-the Troms $\varnothing$ study. Eur J Epidemiol 32:193-201. https://doi.org/10.1007/s10654-017-0231-5

Sasaki R, Ohya Y, Hayashida S, Maeda Y, Murahashi S, Kumamoto S, Tsuji A, Shibata H, Kuramoto K, Hayashi H, Kuriwaki K, Iizaka M, Nakahara O, Inomata Y (2020) A case of Trousseau's syndrome due to intrahepatic cholangiocarcinoma with an extremely high level of CA19-9. Surg Case Rep 6:75. https://doi.org/10. 1186/s40792-020-00835-8

Schorling RM, Pfrepper C, Golombek T, Cella CA, Muñoz-Unceta N, Siegemund R, Engel C, Petros S, Lordick F, Knödler M (2020) Evaluation of biomarkers for the prediction of venous thromboembolism in ambulatory cancer patients. Oncol Res Treat. https:// doi.org/10.1159/000508271
Sorensen HT, Mellemkjaer L, Olsen JH, Baron JA (2000) Prognosis of cancers associated with venous thromboembolism. N Engl J Med 343:1846-1850. https://doi.org/10.1056/NEJM200012213432504

Starling N, Rao S, Cunningham D, Iveson T, Nicolson M, Coxon F, Middleton G, Daniel F, Oates J, Norman AR (2009) Thromboembolism in patients with advanced gastroesophageal cancer treated with anthracycline, platinum, and fluoropyrimidine combination chemotherapy: a report from the UK national cancer research institute upper gastrointestinal clinical studies group. J Clin Oncol 27:3786-3793. https://doi.org/10.1200/JCO.2008.19.4274

Sundbøll J, Veres K, Horváth-Puhó E, Adelborg K, Sørensen HT (2018) Risk and prognosis of cancer after lower limb arterial thrombosis. Circulation 138:669-677. https://doi.org/10.1161/ CIRCULATIONAHA.117.032617

van Es N, Ventresca M, Di Nisio M, Zhou Q, Noble S, Crowther M, Briel M, Garcia D, Lyman GH, Macbeth F, Griffiths G, Iorio A, Mbuagbaw L, Neumann I, Brozek J, Guyatt G, Streiff MB, Baldeh T, Florez ID, Gurunlu Alma O, Agnelli G, Ageno W, Marcucci M, Bozas G, Zulian G, Maraveyas A, Lebeau B, Lecumberri R, Sideras K, Loprinzi C, McBane R, Pelzer U, Riess H, Solh Z, Perry J, Kahale LA, Bossuyt PM, Klerk C, Büller HR, Akl EA, Schünemann HJ (2020) The Khorana score for prediction of venous thromboembolism in cancer patients: an individual patient data meta-analysis. J Thromb Haemost. https://doi.org/10.1111/ jth. 14824

Verso M, Agnelli G, Barni S, Gasparini G, LaBianca R (2012) A modified Khorana risk assessment score for venous thromboembolism in cancer patients receiving chemotherapy: the Protecht score. Intern Emerg Med 7:291-292. https://doi.org/10.1007/ s11739-012-0784-y

Wahrenbrock M, Borsig L, Le D, Varki N, Varki A (2003) Selectinmucin interactions as a probable molecular explanation for the association of Trousseau syndrome with mucinous adenocarcinomas. J Clin Invest 112:853-862. https://doi.org/10.1172/JCI20 0318882

Wang Y, Li J, Xia Y, Gong R, Wang K, Yan Z, Wan X, Liu G, Wu D, Shi L, Lau W, Wu M, Shen F (2013) Prognostic nomogram for intrahepatic cholangiocarcinoma after partial hepatectomy. J Clin Oncol 31:1188-1195. https://doi.org/10.1200/JCO.2012.41.5984

White RH, Chew HK, Zhou H, Parikh-Patel A, Harris D, Harvey D, Wun $T$ (2005) Incidence of venous thromboembolism in the year before the diagnosis of cancer in 528,693 adults. Arch Intern Med 165:1782-1787. https://doi.org/10.1001/archinte.165.15.1782

Woei-A-Jin FJSH, Tesselaar MET, Garcia Rodriguez P, Romijn FPHTM, Bertina RM, Osanto S (2016) Tissue factor-bearing microparticles and CA19.9: two players in pancreatic cancerassociated thrombosis? Br J Cancer 115:332-338. https://doi. org/10.1038/bjc.2016.170

Yue T, Maupin KA, Fallon B, Li L, Partyka K, Anderson MA, Brenner DE, Kaul K, Zeh H, Moser AJ, Simeone DM, Feng Z, Brand RE, Haab BB (2011) Enhanced discrimination of malignant from benign pancreatic disease by measuring the CA 19-9 antigen on specific protein carriers. PLoS ONE 6:e29180. https://doi.org/10. 1371/journal.pone.0029180

Yuri T, Kato K, Hirohara Y, Kinoshita Y, Emoto Y, Yuki M, Yoshizawa K, Tsubura A (2014) Trousseau's syndrome caused by intrahepatic cholangiocarcinoma: an autopsy case report and literature review. Case Rep Oncol 7:376-382. https://doi.org/10.1159/000363689

Publisher's Note Springer Nature remains neutral with regard to jurisdictional claims in published maps and institutional affiliations. 